\title{
IS PLANTINGA A FRIEND OF EVOLUTIONARY SCIENCE?
}

MICHAEL BERGMANN

Purdue University

Where the Conflict Really Lies (WTCRL) is a superb book, on a topic of great importance, by a philosopher of the highest calibre. There is much to learn from it, much to critically engage, much to inspire further work by others. In this article, I will focus on the question of whether Plantinga is a friend of evolutionary science.

It might seem that the obvious answer is 'yes'. In WTCRL, he sings the praises of science (pp. xi \& 3-5) and argues that science fits well within his Christian worldview (pp. 266-303). ${ }^{1}$ Elsewhere he claims that he likes science more than those who chide him for not liking it enough. ${ }^{2}$ But not all are convinced. After reading WTCRL, Michael Ruse says that Plantinga has a 'real religious-based bias against modern science, that he 'simply isn't prepared to take seriously modern science', and that despite Plantinga's protests to the contrary, he accepts [Intelligent Design Theory] over modern evolutionary theory, especially the dominant modern Darwinian evolutionary theory.' And according to Daniel Dennett, Plantinga is a poor student of biology because he doesn't recognize that

\footnotetext{
${ }^{1}$ Page references in the text are to Alvin Plantinga, Where the Conflict Really Lies (New York: Oxford University Press, 2011).

2 See Alvin Plantinga's letter to the editor of The Chronicle of Higher Education (April 11, 2010), in which he responds to a Chronicle article by Michael Ruse. Plantinga's letter can be found online at <http://chronicle.com/article/Evolution-Shibbolethsand/64990/> [accessed 17/09/2013].

${ }^{3}$ The first two quotations are from Michael Ruse, 'How Not to Solve the ScienceReligion Conflict', The Philosophical Quarterly, 62 (2012), 620-5. The third is from 'Alvin Plantinga and Intelligent Design', which Ruse posted on the 'Brainstorm' blog in The Chronicle of Higher Education (December 14, 2011) at <http://chronicle.com/blogs/ brainstorm/alvin-plantinga-and-intelligent-design/42185> [accessed 17/09/2013].
} 
evolution is a random, unguided process. ${ }^{4}$ So does Plantinga accept contemporary evolutionary theory? Does he accept Darwin's theory of natural selection operating in conjunction with random genetic mutations? In short: is he a friend of evolutionary science? Or does he instead endorse that component of Intelligent Design Theory that claims that the evidence from evolutionary science shows that God must have tinkered via miracles with the unfolding of the evolutionary process?

The very fact that the answers to these questions are in doubt suggests that something is amiss. Who is to blame for this confusion? Some might blame Plantinga for not being sufficiently clear on these topics. Others might blame his readers for not paying careful enough attention to what he wrote. Here's a different suggestion: even if his readers' lack of clarity about his views is partially due to one or the other of the two causes just mentioned, it's due in large part to the fact that this is a hot-button issue and Plantinga's views resist simple formulation. If one ventures an opinion on a hot-button issue, where people are ready to object strongly if they think you hold the wrong view, a nuanced statement of a complicated view stands a good chance of making people think you are subtly trying to mask your dissent from the position they hold.

My goal here is to bring some clarity to this issue by considering Plantinga's answers in WTCRL to certain questions, framed in a way that will hopefully reduce confusion. What we want to get clear on is whether Plantinga, in WTCRL, is opposing evolutionary science. I hope to make headway on this matter as follows. First, I will consider what sorts of things count as opposing evolutionary science. Second, I will highlight three key questions, one having to do with whether God is specially involved in evolutionary history, and the other two having to do with the rationale for the answer to the first question. Third, I will examine various answers to these three key questions, including Plantinga's in WTCRL, and consider which of them are unfriendly to evolutionary science. I will close with a few additional questions for Plantinga.

${ }^{4}$ Or at least it seems this is Dennett's view, given the following remarks by Jennifer Schuessler in 'Philosopher Sticks Up for God', The New York Times (December 13, 2011), which can be found online at <http://www.nytimes.com/2011/12/14/books/alvinplantingas-new-book-on-god-and-science.html> [accessed 17/09/2013]: 'Mr. Dennett was even harsher, calling Mr. Plantinga "Exhibit A of how religious beliefs can damage or hinder or disable a philosopher", not to mention a poor student of biology. Evolution is a random, unguided process, he said, and Mr. Plantinga's effort to leave room for divine intervention is simply wishful thinking.' 


\section{WHAT COUNTS AS OPPOSING EVOLUTIONARY SCIENCE?}

One way to oppose evolutionary science is to oppose what the majority of experts say about evolution. Another way is to oppose what the evidence from evolutionary science shows. If the majority of experts can be wrong about what the evolutionary evidence shows, then it's possible to oppose what they say without opposing what the evolutionary evidence shows. ${ }^{5}$ Would that count as opposing evolutionary science (in a way that is unfriendly to such science)? Probably not, given that it can be intelligently done in a way that contributes to the progress of science. But if anyone does oppose what most experts say about evolution and yet claims to support what the evolutionary evidence shows, there will be understandable suspicion and a demand for strong arguments showing that most experts are mistaken about what the evidence shows. This is especially true if the challenger is not an expert in evolutionary biology. Thus, although not opposing what the evolutionary evidence shows is a more important ingredient in friendship with evolutionary science than not opposing what most experts in evolutionary biology say, the latter is a relevant consideration when thinking about whether someone is a friend of evolutionary science.

Notice that one can disagree with the experts in stronger or weaker ways about what the evolutionary evidence shows. Suppose that most experts in evolutionary biology think that the evolutionary evidence shows that $\mathrm{p}$. One might disagree with the experts by thinking any one of the following:

(i) the evidence supports not-p;

(ii) the evidence does not support p;

(iii) it isn't clear whether the evidence supports p;

(iv) the evidence supports $\mathrm{p}$ but not as strongly as the experts think. ${ }^{6}$

${ }^{5}$ This possibility helps us to make sense of the review of WTCRL by Bradley Monton and Logan Paul Gage - see the International Journal for Philosophy of Religion, 72 (2012), 53-57 - in which they suggest that it might be better for Plantinga to claim that his views are 'compatible with all major empirical findings of evolutionary biology, rather than Darwinian theory itself' (as espoused by Darwin and by leading Darwinians).

${ }^{6}$ Or a person might disagree with the experts by thinking the evidence supports $\mathrm{p}$ while the experts think one of the following:

(i) the evidence supports not-p;

(ii) the evidence does not support p;

(iii) it isn't clear whether the evidence supports p;

(iv) the evidence supports $p$ but not as strongly as that person thinks. 
Moving from (i) to (iv), we move from stronger to weaker ways of disagreeing with the experts. Disagreeing with the experts in way (i) will create much more suspicion and require much more defence than disagreeing with them in way (iv). Likewise, friendship with science is more likely to be jeopardized by disagreeing with the experts in way (i) than by disagreeing with them in way (iv). Hence, in determining whether someone is a friend of science, it is important to be clear on what sort of disagreement that person has with the experts.

It's also important to distinguish opposing evolutionary science from each of the following:

(a) holding views about evolution that aren't supported by scientific evidence (evolutionary or otherwise);

(b) holding views about evolution that aren't held by the majority of experts in evolutionary biology.

With regard to (a), many scientists believe - for religious reasons and not on the basis of scientific evidence - in the central miracle of Christianity, namely, that Jesus rose from the dead. ${ }^{7}$ This doesn't count as opposing what the scientific evidence shows because the scientific evidence shows only that, given the causal closure of the physical universe, events such as the resurrection of Jesus never have happened and never will. ${ }^{8}$ Scientific evidence doesn't tell us that the physical universe is causally closed or that that particular alleged miracle didn't occur or that there is no adequate religious evidence for believing that such a miracle occurred. Similarly, believing, for religious reasons, that God performed a particular miracle in evolutionary history doesn't automatically count as opposing evolutionary science. Evolutionary biology tells us the mechanisms by which evolutionary history unfolds when there is no special divine (i.e., miraculous) involvement, but not whether there ever was such

${ }^{7}$ Consider, for example, Kenneth Miller, a biologist at Brown University who is a vocal opponent of the Intelligent Design movement, and Francis Collins, who was one of the leaders of the Human Genome Project. Both of these prominent scientists are Christians who believe in miracles central to the Christian faith, miracles such as the virgin birth or the resurrection of Christ. See Kenneth Miller, Finding Darwin's God (New York: Harper Collins Publishers, 1999), pp. 239-40, and Francis Collins, The Language of God (New York: Free Press, 2006), pp. 221-3.

${ }^{8}$ Under certain interpretations of quantum mechanics, this might not be true (see WTCRL pp. 94-6 \& 118-9 for some discussion of this point). But at the very least, we could say that science shows that, given the causal closure of the physical universe, such events are astronomically improbable. 
involvement (just as medical and biological science tells us what happens with dead bodies when there is no special divine involvement, but not whether there ever was such involvement).

With regard to (b), most experts in evolutionary biology think that Jesus did not rise from the dead (presumably because they don't think they have any scientific evidence for believing this and they don't think they have any good religious evidence either). A scientist who is not in this majority might recognize this fact about these experts, acknowledge that there is insufficient scientific evidence for believing in Jesus' resurrection, and yet still believe, for religious reasons, that that particular miracle occurred. This wouldn't count as opposing science, since the experts in evolutionary biology aren't, as such, experts on whether the physical universe is causally closed or whether God exists or whether God raised Jesus from the dead or whether religious evidence for believing in such a miracle is adequate. ${ }^{9}$ The same points hold if we are talking about miraculous involvement on a particular occasion in the unfolding of evolutionary history. Someone might grant that most experts in evolutionary biology think no such miracle occurred and that we lack scientific evidence for believing in such a miracle and yet still believe, for religious reasons, that such a miracle occurred on a particular occasion. This wouldn't automatically count as opposing science any more than believing in the resurrection of Christ automatically counts as opposing science. ${ }^{10}$

Also related to (b) is the fact that it's important to distinguish what most experts say about evolution from what they say about what the evolutionary evidence shows. It may be that the most experts say that

${ }^{9}$ One problem is that scientists simply don't have enough data to determine via scientific means exactly what happened at all times and places in the past. Hence, as Kenneth Miller says at Edge.org: 'Claims of demonstrative miracles in the past, such as the virgin birth or the resurrection cannot be tested empirically, because there are no data from which to work. On such claims, science has nothing to say one way or the other'. Miller's comments can be found online at: <http://www.edge.org/3rd_culture/ coyne09/coyne09_index.html\#miller> [accessed 17/09/2013].

${ }^{10}$ One would, of course, want to consider what the religious evidence is for believing in such a miracle (just as in the case of believing in the resurrection of Jesus). But in evaluating such evidence, one's expertise as a scientist or evolutionary biologist might not be especially relevant. For some discussion of the religious evidence for believing that Jesus was raised from the dead (or that God intentionally brought about humans), see Alvin Plantinga, Warranted Christian Belief (New York: Oxford University Press, 2000), pp. 170-84, 241-89, \& 374-80. 
evolutionary history is unguided by $\mathrm{God}^{11}$ but they wouldn't say that the evolutionary evidence shows that evolutionary history is unguided by God. Opposing the experts when they aren't speaking about what the evidence shows is much less likely to count as opposing science. Moreover, if most experts did say that the scientific evidence shows that evolutionary history is unguided by God, then (on this matter) nonexperts don't owe them the same deference, since their expertise hasn't qualified them for drawing this sort of theological conclusion from the scientific evidence. Hence, opposing experts in evolutionary biology when they draw this theological conclusion from the evidence is much less likely to count as opposing what the evidence shows or being unfriendly to evolutionary science.

\section{THREE KEY QUESTIONS}

We are looking into whether Plantinga is a friend of evolutionary science. The main reason people think he isn't a friend of evolutionary science is that they are concerned about his views on God's involvement in the unfolding of evolutionary history. Thus, the key questions I want to focus on have to do with what one thinks about God's involvement in evolutionary history and why one thinks what one does. It's important to consider both sorts of questions. In the previous section, we saw that when considering whether someone is opposing science in thinking a miracle, such as the resurrection of Jesus, has occurred - it matters why they think that miracle has occurred, in particular, whether they think the scientific evidence shows it or whether they believe it on the basis of religious evidence alone.

Before getting to the three key questions, I'll need to do a little more stage setting. First, how shall we think of evolution? Following Plantinga, we can say that it includes the common ancestry thesis (that terrestrial life originated at one place on earth and all subsequent earthly life descended from it), the thesis of descent with modification (that the diversity of living things arose by way of offspring differing in small ways from their immediate ancestors), and the progress thesis (that life has progressed from simple unicellular life to more complex organisms such as humans). Plantinga endorses these three theses, along with the view that the process has taken a long time (i.e., most of the earth's 4.5

${ }^{11}$ Perhaps because they think there is no God or because they have views on what God would prefer to do or on how best to understand the doctrine of divine providence.

${ }^{12}$ See WTCRL, pp. 8-11 and p. 41, n. 16. 
billion years). ${ }^{12}$ If we say that endorsing these four claims is sufficient for endorsing evolution, then clearly Plantinga does endorse evolution.

A further question is whether Plantinga thinks there are naturalistic mechanisms driving the evolutionary process - the most popular candidate being natural selection winnowing random genetic mutation. If he does, we can say he endorses Darwinism, which includes the four claims above plus this view about natural mechanisms driving the evolutionary process. ${ }^{13}$ But the question of whether Plantinga endorses Darwinism, so understood, is complicated by the fact that he thinks that God is intimately involved with the unfolding of evolutionary history, even if that unfolding process is driven by a mechanism relying on random genetic mutation. ${ }^{14}$ Notice that there are two main kinds of ways God might be involved with the evolutionary process: God might act in special ways that depart from the ordinary routine unfolding of the evolutionary process (these special actions are miracles); or God might be involved in an ordinary routine way. Here are some examples of the latter kind of involvement:

Conservationism: At all times that it exists, the entire physical universe depends on God's conserving it in existence with all the causal powers that it and its part have. ${ }^{15}$

Theistic Hidden Variable View (THV): A hidden variable interpretation of quantum mechanics (QM) is true and we live in an ultimately deterministic universe; God set things in motion at the Big Bang and watched the evolutionary process unfold in exactly the way he planned, in accord with the deterministic laws he selected. ${ }^{16}$

Divine Collapse-Causation View (DCC): The GRW interpretation of QM is true, so macroscopic objects like our bodies are definitely located not continuously but only intermittently when the wave

${ }^{13}$ Of course it is also perfectly standard to refer to the combination of these five claims as 'evolution'.

${ }^{14}$ How can genetic mutation be both random and guided by God? Plantinga discusses this question in WTCRL, pp. 11-12 and it comes up in section 3 of this article as well.

${ }^{15}$ According to this doctrine, without divine conservation, the universe would cease to exist like the bubbles in a cup of water disappear when the child stops blowing through the straw in the cup.

${ }^{16}$ On this proposal, you might think God acts in a special out-of-the-ordinary and non-routine way when he sets things up. That may be true. But on this account he doesn't get involved in any special way in the unfolding of evolutionary history; at most he gets specially involved in getting the process started at the Big Bang. 
function collapses, which occurs multiple times per second; and God (rather than nothing at all) causes each successive collapse to go to the particular eigenstate it goes to rather than another. ${ }^{17}$

In each of these three examples, God is intimately involved with the unfolding of the evolutionary process; but his involvement, while genuine, does not result in anything out of the ordinary occurring in evolutionary history, nothing that doesn't happen all the time, as a matter of course.

Of interest, for our purposes, are not these ordinary routine ways God might be involved but, rather, the special ways, out of the ordinary routine, in which God might be involved in the unfolding of evolutionary history. ${ }^{18}$ As an example, consider genetic mutation and suppose that Kenneth Miller is right that quantum indeterminacy is manifested at the level of gene mutation, so that it isn't determined whether a particular mutation will occur; instead, it is only probable to a certain degree that it will occur. ${ }^{19}$ Suppose also that God wants to guarantee the occurrence of that particular mutation and so he gets specially involved and causes it. In fact, suppose that God tinkers in this way with the evolutionary process, not constantly or in regular ways but on numerous occasions. Notice that this sort of tinkering could happen in three different ways. First, it could happen in a way that is in principle undetectable by empirical science. This is because science tells us only that there will be certain probabilistic patterns in the results of indeterministic causal processes, not that any particular undetermined result will occur on a particular occasion.

17 See WTCRL, pp. 115-21 for a fuller development of this view. The nontheistic alternative version of the GRW (Ghirardi-Rimini-Weber) interpretation is, as suggested in the text, that nothing causes these collapses to go to the particular eigenstates they go to rather than to alternative eigenstates (though there may be a predictable probabilistic pattern to the results of the successive collapses). See Giancarlo Ghirardi, 'Collapse Theories', The Stanford Encyclopedia of Philosophy (Winter 2011 Edition), Edward N. Zalta (ed.), <http://plato.stanford.edu/archives/win2011/entries/qm-collapse/> [accessed $17 / 09 / 2013]$.

${ }^{18}$ As Plantinga notes (WTCRL, pp. 94-6), if standard indeterministic interpretations of QM are true, it is difficult to say what counts as out of the ordinary. But perhaps we can agree with Plantinga (WTCRL, pp. 118-19) that we have an intuitive sense of it. The usual examples of miracles (rising from the dead, walking on water, feeding five thousand people with a little bread and fish) are still fine as examples even if indeterministic interpretations of QM are true. Such events, if God really did bring them about, would still count as out of the ordinary divine involvement.

${ }^{19}$ See Finding Darwin's God, pp. 207-14. 
If God tinkers with the gene mutation process in a way that is in accord with the probabilistic patterns scientists have learned to expect, then even if he tinkers fairly often, his involvement will be in principle undetectable by empirical science. ${ }^{20}$ This kind of divine tinkering with the mutation process is compatible with the process being random in the senses in which scientists are warranted in claiming that it is random, since science is in principle ignorant about whether this kind of tinkering occurs. ${ }^{21}$ Second, God could tinker with the evolutionary process in a way that has not been detected by science but which is in principle detectable by science (perhaps because science could in principle discover that some extremely unlikely kinds of events have been occurring surprisingly often). Third, God could do this in a way that is both detectable and actually detected by science. ${ }^{22}$

With this background in place, we can now state the three key questions. Here's the first:

(1) Do you think God is involved in some special, out-of-the-ordinary, non-routine way in the unfolding of evolutionary history?

This question could be answered with a 'yes', a 'no', or a 'maybe'. The second and third questions follow up on the 'yes' and 'maybe' answers to question 1 by asking for the rationale for those answers. To help focus our discussion, I will also mention some possible answers a person might give to these questions: ${ }^{23}$

(2) If your answer to 1 is 'yes,' what is your reason for believing God was specially involved in the unfolding of evolutionary history?

(a) Given the evolutionary evidence, it is prohibitively improbable that there is an evolutionary pathway (that would fit within the allotted time frame and involve only unguided mechanisms such as natural selection, spandrelism, and genetic drift) from simple

20 This sort of point is developed and defended in Peter van Inwagen, 'The Compatibility of Darwinism and Design', in God and Design: The Teleological Argument and Modern Science, ed. Neil A. Manson (New York: Routledge, 2003), pp. 348-63.

${ }^{21}$ If evolutionary scientists claim that the mutation process is random in the sense that God is not tinkering at all, not even in a way that is in principle undetectable by science, they are obviously going beyond what the scientific evidence reveals.

22 Instead of focusing on God's tinkering with indeterministic gene mutation processes, we could have focused on God's tinkering with other evolution-relevant indeterministic processes in the three ways just mentioned (processes affecting not gene mutation but, for example, the environments of organisms in evolutionary history).

${ }^{23}$ The lists of possible answers aren't meant to be exhaustive. 
unicellular life to some actual complex organisms we know of, in which case these organisms are better explained by appeal to at least some special activity of God than by completely unguided naturalistic mechanisms.

(b) Religious evidence of some kind (e.g., sacred texts or religious experience) strongly suggests that God intentionally brought about humans and that could happen only if God was specially involved in the unfolding of evolutionary history (otherwise, the existence of humans wouldn't be guaranteed).

(c) Religious evidence of some kind strongly suggests in some other way that God was specially involved in the unfolding of evolutionary history.

(3) If your answer to 1 is 'maybe,' what is your reason for believing that God may have been specially involved in the unfolding of evolutionary history? ${ }^{24}$

(a) Given the evolutionary evidence, it may, for all we know, be prohibitively improbable that there is an evolutionary pathway (that would fit within the allotted time frame and involve only unguided mechanisms such as natural selection, spandrelism, and genetic drift) from simple unicellular life to some actual complex organisms we know of, in which case these organisms may be better explained by appeal to at least some special activity of God than by completely unguided naturalistic mechanisms.

(b) Religious evidence of some kind (e.g., sacred texts or religious experience) strongly suggests that God intentionally brought about humans in particular and that may, for all we know, have happened via God's being specially involved in the unfolding of evolutionary history.

(c) Religious evidence of some kind suggests in some other way that God may, for all we know, have been specially involved in the unfolding of evolutionary history.

In the next section, I will be considering which of these answers are unfriendly to evolutionary science and which are not.

${ }^{24}$ The possible answers listed here are very much like the possible answers listed for question 2, except that here they're in the 'may, for all we know be true' form rather than the 'is true' form. 


\section{WHICH ANSWERS ARE UNFRIENDLY TO EVOLUTIONARY SCIENCE?}

Let's begin by considering a 'yes' answer to question 1 . Notice that someone could say 'yes' to 1 , reject option $2 \mathrm{a}$, and take option $2 \mathrm{~b}$ or $2 c$ instead. In so doing, that person would be saying that God's special involvement is not of the 'actually scientifically detected' variety but is, instead, of the 'scientifically undetected but detectable' variety or the 'in principle scientifically undetectable' variety. ${ }^{25}$ For reasons mentioned in section 1 , options $2 \mathrm{~b}$ and $2 \mathrm{c}$ don't seem to count as opposing evolutionary science any more than one opposes science by believing, for religious reasons, in the resurrection of Christ while acknowledging that we lack scientific evidence for this belief. But what shall we say of someone who says 'yes' to 1 and takes option $2 a$ ? This seems to be the position endorsed by Behe. ${ }^{26}$ Does this count as opposing evolutionary science? It is widely believed that it does, on the grounds that, contra Behe, the evidence does not suggest that an evolutionary pathway (of the kind mentioned in 2a) to some known organism is prohibitively improbable. ${ }^{27}$

Consider next a 'maybe' response to question 1. At places in WTCRL (e.g., pp. 11-16), Plantinga gives this answer and highlights $3 \mathrm{~b}$ as a rationale for doing so. Does this count as opposing evolutionary science? Consider this question first as applied to the position of taking option $3 \mathrm{~b}$ while rejecting option 3a. This position doesn't claim that the scientific evidence shows that an evolutionary pathway to some known organism is prohibitively improbable or even that it may, for all we know, be prohibitively improbable. Those probability judgments have nothing to do with this position's rationale for saying that God might have been specially involved in evolutionary history. Instead, the rationale has to do with the belief (based on religious evidence, not scientific evidence) that God has intentionally brought about humans. ${ }^{28}$ But how can God

${ }^{25}$ If the person thought it was special involvement of the 'actually scientifically detected' variety, then presumably the person would be taking option 2a.

${ }^{26}$ Michael Behe, Darwin's Black Box (New York: Simon and Schuster, 1996), pp. 39-48 and chs. 3-6.

${ }^{27}$ For a presentation of this evidence, see the following by Kenneth Miller: 'Answering the Biochemical Argument from Design' in God and Design, pp. 292-307; 'The Flagellum Unspun: The Collapse of "Irreducible Complexity" in Debating Design: From Darwin to DNA, eds. William Dembski and Michael Ruse (Cambridge: Cambridge University Press, 2004), pp 81-97; and Finding Darwin's God, chapter 5.

${ }^{28}$ See note 10 for references to discussion of this religious evidence. 
intentionally bring about humans via evolution if the gene mutation on which evolution depends is significantly influenced by quantum level causation, which is widely believed to be indeterministic and random?

There are several possible answers, which were mentioned above. ${ }^{29}$ It may be that THV is true. In that case, gene mutation would still be random from the perspective of current science, in the same sense in which a sequence of coin tosses would be random from our perspective even if we lived in a deterministic universe. ${ }^{30}$ Or it may be that DCC is true and that indeterministic quantum-level causation and any gene mutation significantly affected by it are random from the scientific perspective, despite the fact that each of the many-times-per-second wave-function collapses is caused by God to occur in the way it does. ${ }^{31}$ In that case, evolutionary history could have been intentionally brought about by God, no matter how it went.

Now consider someone who believed, for scientific reasons, in Darwinian evolution and who also believed, for religious reasons, that God intentionally brought about humans. Such a person might think the following: either THV is true or DCC is true or God got specially involved in the unfolding of evolutionary history, tinkering with it in either a scientifically undetectable way or a scientifically detectable but undetected way. ${ }^{32}$ A person who thought this would believe, for religious reasons, that God may, for all we know, have been specially involved in the evolutionary process. Does holding that view count as opposing evolutionary science? It seems not. Thinking that God may have been involved in evolutionary history in a routine way - because either THV

${ }^{29}$ The first two possible answers discussed here (i.e., THV and DCC) don't speak of special involvement by God in evolutionary history. But their relevance to question 3, which does focus on special involvement by God, will become apparent below.

${ }^{30}$ Insofar as 19 th century biologists (who had never heard of quantum indeterminacy) believed that the genetic mutation involved in natural selection was random or by chance, they presumably thought it was random in this sense.

${ }^{31}$ The only difference between the DCC version of evolutionary history and an atheistic GRW version of it is that in the former case God causes each spontaneous collapse and in the latter case nothing causes these collapses to turn out precisely as they do. Either way, the actual physical history is the same. And the former is random in every way that science can confirm that the latter is random. (It's true that the evolutionary process is not random in the DCC case if being random requires that God is not causing the genetic mutations involved. But science doesn't show us that the evolutionary process is random in that sense.)

${ }^{32}$ Since we're focusing on the sort of position taken by someone who rejects $3 \mathrm{a}$, the option of God's tinkering in a scientifically detected way isn't among the disjuncts. 
or DCC is true - presents no challenge at all to the conclusions of the majority of experts in evolutionary science; it simply accepts them and adds that God is behind it all. And thinking, for religious reasons, that God may, for all we know, have been specially involved in evolutionary history in a way that is scientifically undetectable, or at least scientifically undetected, also doesn't oppose any conclusions of evolutionary biology no more than does a belief, held for religious reasons, that a blind man may, for all we know, have been miraculously healed by Jesus, despite the fact that we have no scientific evidence for this conclusion.

So, by endorsing $3 \mathrm{~b}$, Plantinga isn't, thereby, opposing evolutionary science. However, Plantinga also endorses 3a. He disagrees with Behe, who thinks that we can see, in light of the evolutionary evidence, that evolutionary pathways to certain organisms (e.g., bacterial flagellum) are prohibitively improbable..$^{33}$ But he also disagrees with Dawkins who thinks we can see, in light of the evolutionary evidence, that evolutionary pathways to certain organisms (e.g., the mammalian eye) are not prohibitively improbable. Plantinga's view is that we simply can't tell whether these pathways are prohibitively improbable. ${ }^{34}$ Does this oppose evolutionary science? And if so, how much?

Dawkins thinks that the evolutionary evidence supports the following claim:

EP: A not-too-long evolutionary pathway from unicellular life to the mammalian eye (in a system without any special divine tinkering) is not prohibitively improbable. ${ }^{35}$

Plantinga disagrees, not by thinking the evolutionary evidence supports the denial of EP but only by thinking it isn't clear that it supports EP. Is this opposing evolutionary science? It threatens to only if (a) most experts in evolutionary biology agree with Dawkins that the evolutionary evidence supports EP and (b) they are right. Let's suppose that's so. Even then Plantinga's disagreement only weakly opposes science in the sense that he says it isn't clear that a certain probability assessment, endorsed by the majority of the experts, is correct. Does that make him unfriendly to science? If that's unfriendly, it's not very unfriendly.

${ }^{33}$ WTCRL, pp. 229-36.

${ }^{34}$ WTCRL, pp. 18-24 \& 252-56.

${ }^{35}$ I say 'not-too-long' because the evidence we have suggests that the evolutionary pathway in question must be shorter than 4 billion years. 


\section{SOME QUESTIONS FOR PLANTINGA}

Our goal has been to consider whether Plantinga is a friend of evolutionary science. We've discovered one way in which he might be at least a little unfriendly toward science: he thinks it isn't clear whether the evolutionary evidence supports EP whereas most experts, who presumably are better judges than he is on this matter in virtue of their scientific training, think the evolutionary evidence supports EP (or so we're assuming). In light of the discussion above, my first two questions for Plantinga are:

(1) Am I right in saying that, in WTCRL, your answer to key question 1 is 'maybe' and that you take both option $3 \mathrm{a}$ and option $3 \mathrm{~b}$ in response to question 3 ?

(2) Do you think that your view on whether the evolutionary evidence supports EP makes you at least somewhat unfriendly toward evolutionary science?

There is an additional way in which Plantinga has appeared to some to be unfriendly to evolutionary science. It has to do with some older work by Plantinga, not mentioned in WTCRL, in which he seemed even more unfriendly to evolutionary science, thinking (contrary to what most experts tell us) that it is more likely that various species were specially created ${ }^{36}$ by God (and that the common ancestry thesis is false) than that Darwinian evolution is true. There he wrote:

[I]t isn't particularly likely, given the Christian faith and the biological evidence, that God created all the flora and fauna by way of some mechanism involving common ancestry.

and

Perhaps [God created the multifarious forms of life] by broadly evolutionary means, but then again perhaps not. At the moment, 'perhaps not' seems the better answer. ${ }^{37}$

${ }^{36}$ God's specially creating a species is opposed to the thesis of common ancestry. It is thus quite different from the view that God was specially involved in the unfolding of evolutionary history (tinkering on occasion with the gene mutation process or the environmental conditions), which is perfectly compatible with the thesis of common ancestry.

37 See Alvin Plantinga, 'When Faith and Reason Clash: Evolution and the Bible', Christian Scholar's Review, 21 (1991), 28 \& 29. See also p. 22 where he says: 'The two hypotheses to be compared are (1) the claim that God has created us in such a way that 
In light of these quotations, my third question for Plantinga is:

(3) Do you now disagree with your earlier claims (e.g., in 'When Faith and Reason Clash') suggesting that, in light of the evolutionary evidence, Darwinism is unlikely to be true?

Again, the purpose of these remarks has been to clarify whether Plantinga is a friend of evolutionary science. My hope is that his response to this article, including questions (1)-(3), will be helpful in that regard. ${ }^{38}$

(a) all of contemporary plants and animals are related by common ancestry, and (b) the mechanism driving evolution is natural selection working on random genetic variation and (2) the claim that God created mankind as well as many kinds of plants and animals separately and specially, in such a way that the thesis of common ancestry is false. Which of these is the more probable, given the empirical evidence and the theistic context? I think the second, the special creation thesis, is somewhat more probable with respect to the evidence (given theism) than the first.'

${ }^{38}$ Thanks to Jeffrey Brower, Paul Draper, Patrick Kain, Alvin Plantinga, and Michael Rea for comments on earlier drafts. 